\title{
Monte Carlo Evaluation of the Impact of Subsequent Strokes on Backflashover Rate
}

\author{
Fabio Massimo Gatta, Alberto Geri, Stefano Lauria and Marco Maccioni *
}

Department of Astronautics, Electric and Energy Engineering, Sapienza University of Rome, Rome, 00184, Italy; fabiomassimo.gatta@uniroma1.it (F.M.G.); alberto.geri@uniroma1.it (A.G.); stefano.lauria@uniroma1.it (S.L.)

* Correspondence: marco.maccioni@uniroma1.it; Tel.: +39-06-4458-5540

Academic Editor: Rodolfo Araneo

Received: 12 January 2016; Accepted: 19 February 2016; Published: 26 February 2016

\begin{abstract}
The paper deals with the impact of subsequent strokes on the backflashover rate (BFR) of HV overhead transmission lines (OHLs), assessed by means of an ATP-EMTP Monte Carlo procedure. The application to a typical $150 \mathrm{kV}$ Italian OHL is discussed, simulating several tower grounding system arrangements. Subsequent strokes parameters are added to the statistical simulation variables: peak current, front time, time-to-half value, lightning polarity, line insulation withstand, lightning location and phase angle of the power frequency voltage. The input data are fed to an ATP-EMTP complete circuit model of the OHL, including line insulation, lightning representation and tower grounding system, the latter simulated by a pi-circuit model able to simulate the effects due to propagation and soil ionization, at modest computational costs. Numerical results evidence a non-negligible BFR increase (in relative terms) due to subsequent strokes: for spatially concentrated grounding systems the BFR increase approximatively vary in inverse proportion with the low frequency grounding resistance, whereas for spatially extended grounding systems the BFR increase depends on the grounding system behavior at high frequencies.
\end{abstract}

Keywords: backflashover rate; HV overhead line; grounding system; ATP-EMTP; Monte Carlo; subsequent strokes

\section{Introduction}

Most faults affecting overhead transmission lines (OHLs) at HV and EHV level are caused by lightning strokes to the line itself (i.e., direct lightning). Due to the presence of shield wires, strokes to tower peaks and the shield wires largely prevail on those to phase conductors; as a consequence, faults associated with tower/shield wire strokes (backflashovers) are also more numerous than those caused by strokes to phase conductors (shielding failures). Due to the random nature of lightning and line insulation behavior, quantitative analyses aimed at assessing backflashovers require, in principle, a multivariable, statistical approach, ideally suited to Monte Carlo methods.

The main drawback of every Monte Carlo-based approach is that a large number of simulations is required in order to obtain convergence. Since the tower grounding system impulse response plays a key role in the lightning performance of OHLs, especially if spatially extended grounding system arrangements are employed (e.g., in medium-to-high resistivity soils), backflashover analyses become too computationally expensive when accurate grounding system models [1-4] are implemented. Therefore, on one hand simplified methods not based on a Monte Carlo approach were developed, notably the CIGRE [5] and IEEE [6,7] procedures. On the other hand, several procedures based on a Monte Carlo approach have been proposed [8-13], but adopting very simple grounding system models. In [8], a user-defined tower footing resistance distribution is considered. In [10], impulse current 
resistances, derived from laboratory test data, simulate concentrated grounds. In [11], a constant resistance is used, whereas in [12] grounding system model consists of a linear lumped resistance $R$ and an inductance L. Lastly, in [13] the tower footing "impulse resistance" is approximated by the non-linear resistance model proposed in [1] and a log-normal distribution of the low-frequency resistance is given. In previous papers, the authors proposed a simplified (yet accurate) grounding system model [14-17], able to reproduce the lightning responses, including soil ionization phenomena, at modest computational costs; the model has been subsequently employed in an ATP-EMTP-based Monte Carlo procedure in order to assess the backflashover rate (BFR) of OHLs. All these studies, however, only focus on the first stroke, since it almost invariably has the highest peak current in a given lightning flash. In recent years, the influence of the smaller (but steeper) subsequent strokes on BFR was studied in several non-Monte Carlo-based papers [18-20], showing a non-negligible BFR increase. In [18-20], however, grounding systems are simulated by linear lumped resistances, thus not taking into account both soil ionization (relevant especially in low-resistivity soils) and the high-frequency response to the steeper wavefronts associated to subsequent strokes (relevant especially in high-resistivity soils, where spatially extended grounding systems are employed).

The paper presents a comprehensive ATP-EMTP-based backflashover performance evaluation tool, building up subsequent strokes into the authors' Monte Carlo procedure [21-23]. The latter previously only took into account first strokes, whereas the presented procedure assumes a number of subsequent strokes statistically variable in accordance with data reported in [24]. Results pertaining to typical $150 \mathrm{kV}-50 \mathrm{~Hz}$ Italian OHLs equipped with a wide variety of grounding systems, both spatially concentrated and extended (i.e., counterpoises and crowfoot arrangements), are presented, showing the effect of subsequent strokes on BFR estimation. The paper is structured as follows: Section 2 recalls the BFR calculation procedure and Section 3 details ATP-EMTP simulation models, whereas Section 4 reports the statistical variables and parameters used in the procedure; lastly, simulation results are shown and analyzed in Section 5.

\section{Basic Considerations}

The statistical ATP-EMTP-based Monte Carlo procedure generates $N_{\text {tot }}$ lightnings, which are supposed to fall within a $1 \mathrm{~km}$-wide zone having the OHL placed in the center. The $N_{L}$ lightnings impinging on the line are found via the Eriksson's electrogeometric model [25], assuming that all strokes terminate on towers. Such strokes are simulated with ATP-EMTP, in order to check the occurrence of backflashover. The BFR of the line (faults $/ 100 \mathrm{~km} \cdot$ year) is assessed as:

$$
B F R=0.6 \cdot \frac{N_{B F O}}{N_{t o t}} \cdot N_{g} \cdot 100
$$

where $N_{B F O}$ is the total number of backflashovers resulting from simulations, $N_{g}$ is the ground flash density (flashes $/ \mathrm{km}^{2}$. year) and 0.6 is a numerical coefficient which multiplies the BFR calculated considering only strokes to tower, in order to account for strokes within the span, as in [26]. Figure 1 shows a flow-chart of the procedure [21-23] (in the flow-chart $N$ is the number of the current simulation, $T_{g N}$ is the $N_{B F O} / N$ ratio calculated by the procedure and $\varepsilon_{N}$ is the convergence error). 


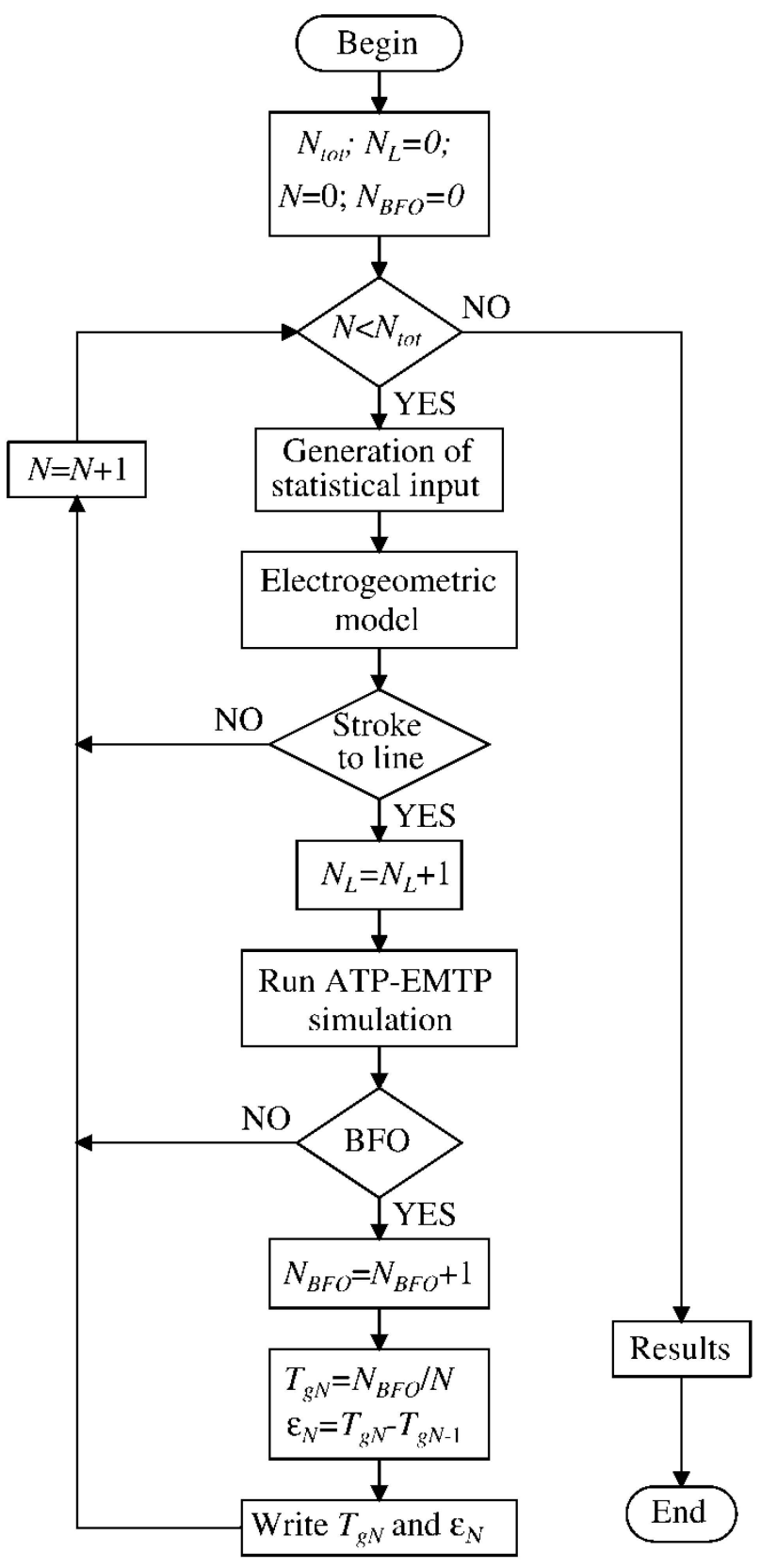

Figure 1. Flow-chart of the procedure.

\section{System Modeling}

The simulated system is a $10 \mathrm{~km}$ long stretch of a typical Italian $150 \mathrm{kV}-50 \mathrm{~Hz}$ OHL. Seven different tower grounding arrangements were considered: three concentrated ones, shown in Figure 2, and four spatially extended ones, shown in Figure 3; main features of the simulated grounding systems are reported in Table 1. 

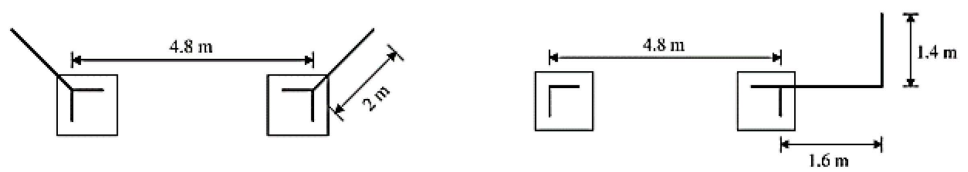

a)

b)
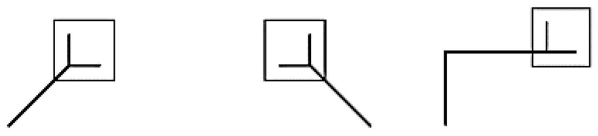

$+$

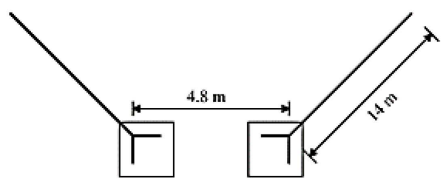

c)

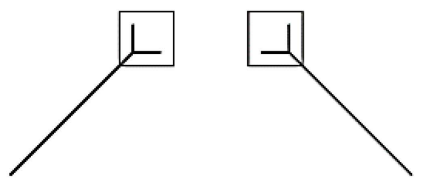

Figure 2. Sketches of the simulated concentrated grounding systems: (a) GS 1; (b) GS 2; (c) GS 3.
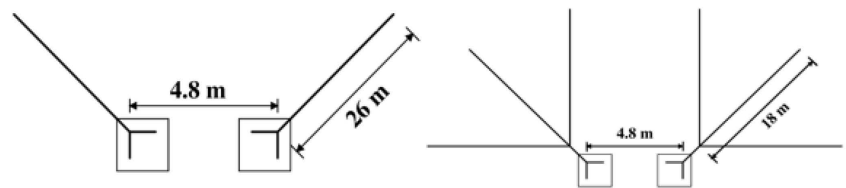

a)

b)

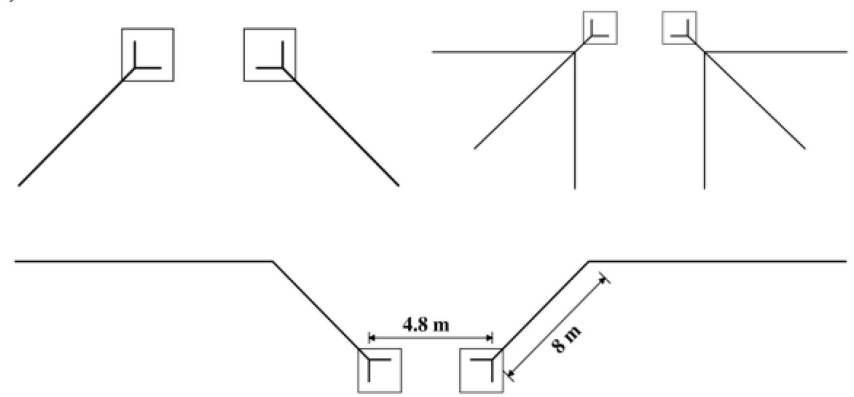

c)

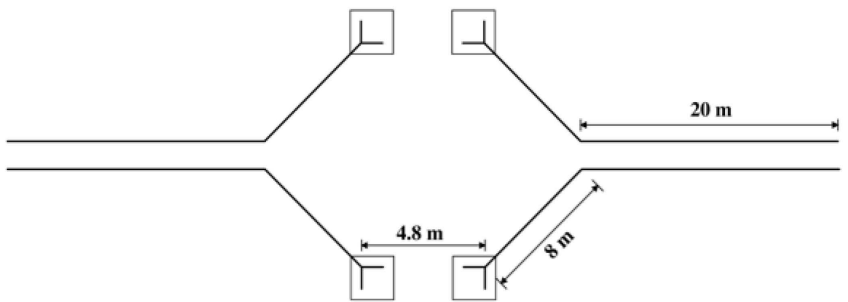

d)

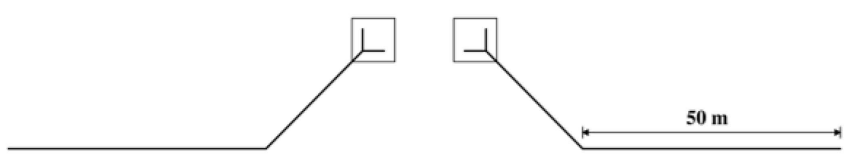

Figure 3. Sketches of the simulated spatially extended grounding systems: (a) GS 4; (b) GS 5; (c) GS 6; (d) GS 7. 
Table 1. Main features of the simulated grounding systems.

\begin{tabular}{|c|c|c|c|c|}
\hline $\begin{array}{l}\text { Grounding system } \\
\text { configuration }\end{array}$ & $\begin{array}{c}\text { Soil resistivity } \rho_{\mathrm{g}} \\
(\Omega \cdot \mathrm{m})\end{array}$ & $\begin{array}{c}\text { Soil relative } \\
\text { permittivity } \varepsilon_{\mathbf{r}}\end{array}$ & Burying depth (m) & $\mathrm{R} @ 50 \mathrm{~Hz}(\Omega)$ \\
\hline GS 1 & 100 & 50 & 0.8 & 6.3 \\
\hline GS 2 & 100 & 50 & 0.8 & 11.42 \\
\hline GS 3 & 500 & 43 & 0.8 & 14.95 \\
\hline GS 4 & 1000 & 35 & 0.8 & 19.1 \\
\hline GS 5 & 2000 & 19 & 0.8 & 30.4 \\
\hline GS 6 & 1000 & 35 & 0.8 & 24.05 \\
\hline GS 7 & 2000 & 19 & 0.8 & 24.5 \\
\hline
\end{tabular}

\subsection{OHL Model}

The ATP-EMTP OHL model consists of 25 line spans, each $400 \mathrm{~m}$ long and simulated by the "JMarti" frequency-dependent model. The single circuit OHL is equipped with single $31.5 \mathrm{~mm}$ ACSR conductors (phases) and a single $11.5 \mathrm{~mm}$ steel conductor (ground wire): Figure 4 shows the outline of the tower. At both ends of the simulated line stretch, the OHL is connected to the line surge impedance matrix: phase conductors are then terminated on a three-phase $150 \mathrm{kV}-50 \mathrm{~Hz}$ voltage system, whereas the shield wire is solidly grounded $[15,16,27]$. Table 2 reports the phase and shield wire conductors coordinates, whereas the phase conductor and the shield wire sags are $11.4 \mathrm{~m}$ and $9.7 \mathrm{~m}$, respectively.

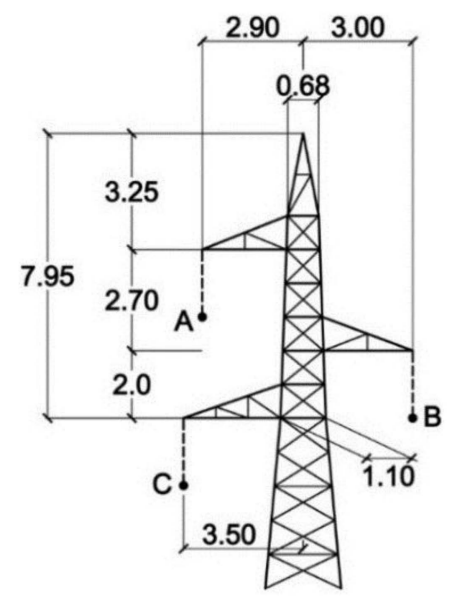

Figure 4. OHL tower head (dimensions in $\mathrm{m}$; the tower height is $31.1 \mathrm{~m}$ ).

Table 2. Phase and shield wire conductor coordinates.

\begin{tabular}{ccccc}
\hline Coordinate & A & B & C & SW \\
\hline $\mathrm{x}(\mathrm{m})$ & -2.9 & 3 & -3.5 & 0 \\
$\mathrm{y}(\mathrm{m})$ & 25.4 & 23.4 & 21.4 & 31.1 \\
\hline
\end{tabular}

\subsection{Line Insulation Model}

Line insulation has been represented by means of the well-established CIGRE Leader Progression Model (LPM), programmed into ATP-EMTP by using "MODELS" language [28]:

$$
\frac{d l}{d t}=k \cdot u(t)\left[\frac{u(t)}{d_{G}-l(t)}-E_{0}\right]
$$

being $d_{G}(m)$ the gap length (1.46 $\mathrm{m}$ in the simulations reported in the paper), $l(t)(m)$ the leader length, $u(t)(\mathrm{kV})$ the voltage across tower insulation, $E_{0}(\mathrm{kV} / \mathrm{m})$ the critical electric field, whereas the speed parameter $k\left(\mathrm{~m}^{2} \cdot \mathrm{kV}^{-2} \cdot \mathrm{s}^{-1}\right)$ is $1.2 \cdot 10^{-6}$ and $1.3 \cdot 10^{-6}$ for positive and negative flashes, respectively. 


\subsection{Lightning Model}

Both first and subsequent strokes have been simulated by the well known "Heidler" current surge function [29] implemented in ATP-EMTP:

$$
i(t)=\frac{I_{P}}{\eta} \cdot \frac{k_{s}^{n}}{1+k_{s}^{n}} \cdot e^{-\frac{t}{\tau_{2}}}
$$

being $I_{P}$ the peak value of the lightning stroke, $k_{S}$ the $t / \tau_{1}$ ratio, $\tau_{1}$ and $\tau_{2}$ time constants establishing the front time and the time-to-half value, respectively, $\eta$ the adjustment constant and $n$ a factor influencing the rate of rise and the time instant of the maximum rate of rise.

\subsection{Grounding System Model}

Tower grounding systems were simulated by means of the simplified pi-circuit model described in $[14,15,17]$ and shown in Figure 5. The pi-circuit model is obtained by synthesizing the full circuit model described in [1] (also accounting for soil ionization), by means of a procedure based on the micro-Genetic Algorithm. Linear circuit elements in Figure $5\left(R_{1}, R_{2}, C_{1}, C_{2}, R, L\right)$ reproduce the frequency response of the non-ionized grounding system in the frequency range $1 \mathrm{~Hz}-1 \mathrm{MHz}$.

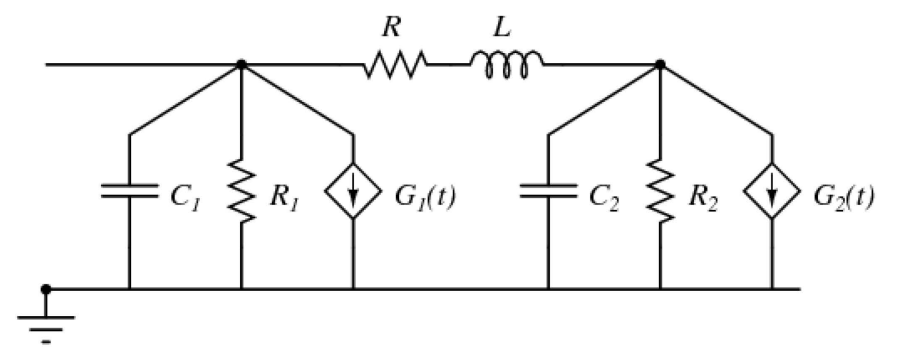

Figure 5. Pi-circuit model.

The ideal voltage-controlled current sources $G_{1}$ and $G_{2}$ simulate the non-linear behavior of the grounding system due to soil ionization and are defined as $(i=1,2)$ :

$$
G_{i}(t)=\frac{V_{R i}(t)}{F_{i}(t)}-\frac{V_{R i}(t)}{R_{i}}
$$

where:

$$
F_{i}(t)=R_{i}-\alpha_{i} \cdot \log \left(10^{-4}+\beta_{i} \frac{V_{R_{i}}(t)}{R_{i}}\right), F_{i} \in\left[10^{-4} ; R_{i}\right]
$$

and $V_{R_{i}}(t)$ is the voltage across the resistor $R_{i}$. The pi-circuit model has been also validated by comparison with two different models, one based on an electromagnetic full-wave approach, the other adopting hybrid circuit-field approach [30], yielding very good results even when subsequent strokes are injected. Numerical values of pi-circuit parameters of the simulated grounding systems are reported in Tables 3 and 4 whereas the impedances in frequency domain (in the frequency range $1 \mathrm{~Hz}-1 \mathrm{MHz}$ ) of the concentrated and spatially extended grounding systems are plotted in Figure 6 . Figure 6a shows that concentrated grounding systems GS 1, GS 2 and GS 3 have a predominant resistive behavior in the whole frequency range of interest, whereas spatially extended ones have a predominant inductive (GS 4, GS 6 and GS 7) and capacitive (GS 5) behavior at high frequencies. 
Table 3. Linear parameter values for pi-type simplified equivalent circuits.

\begin{tabular}{ccccccc}
\hline Grounding System & $\boldsymbol{R}_{\mathbf{1}}(\Omega)$ & $\boldsymbol{R}_{\mathbf{2}}(\Omega)$ & $\boldsymbol{R}(\Omega)$ & $\boldsymbol{L}(\mu \mathbf{H})$ & $\boldsymbol{C}_{\mathbf{1}}(\mathbf{n F})$ & $\boldsymbol{C}_{\mathbf{2}}(\mathbf{n F})$ \\
\hline GS 1 & 27.7 & 1.65 & 6.55 & 0.32 & 0.66 & 25 \\
GS 2 & 14.4 & 10.9 & 44.09 & 5.47 & 0.01 & 15.7 \\
GS 3 & 32.1 & 25.9 & 2.22 & 4.85 & 3.18 & 8.66 \\
GS 4 & 34.12 & 43.27 & 0 & 12.5 & 3.32 & 9 \\
GS 5 & 42.49 & 69.39 & 37.54 & 10.2 & 6.78 & 12.5 \\
GS 6 & 28.75 & 137.35 & 9.54 & 12.5 & 1.08 & 5.67 \\
GS 7 & 40.96 & 60.99 & 0.07 & 28.2 & 2.89 & 10.5 \\
\hline
\end{tabular}

Table 4. Non-linear coefficient values for pi-type simplified equivalent circuits.

\begin{tabular}{ccccc}
\hline Grounding System & $\alpha_{\mathbf{1}}(\Omega)$ & $\alpha_{\mathbf{2}}(\Omega)$ & $\left.\beta_{\mathbf{1}} \mathbf{A}^{-\mathbf{1}}\right)$ & $\left.\beta_{\mathbf{2}} \mathbf{( A}^{-\mathbf{1}}\right)$ \\
\hline GS 1 & 1.204 & 0.045 & 326.6 & 163.1 \\
GS 2 & 0.7 & 0.7 & 0.633 & 850.5 \\
GS 3 & 0.322 & 0.63 & 0.633 & 850.5 \\
GS 4 & 0.406 & 0.285 & 1654.9 & 931.0 \\
GS 5 & 0.005 & 3.142 & 1090.7 & 1847.6 \\
GS 6 & 0.419 & 4.915 & 3.685 & 172.9 \\
GS 7 & 0 & 2.832 & 200.1 & 0.074 \\
\hline
\end{tabular}
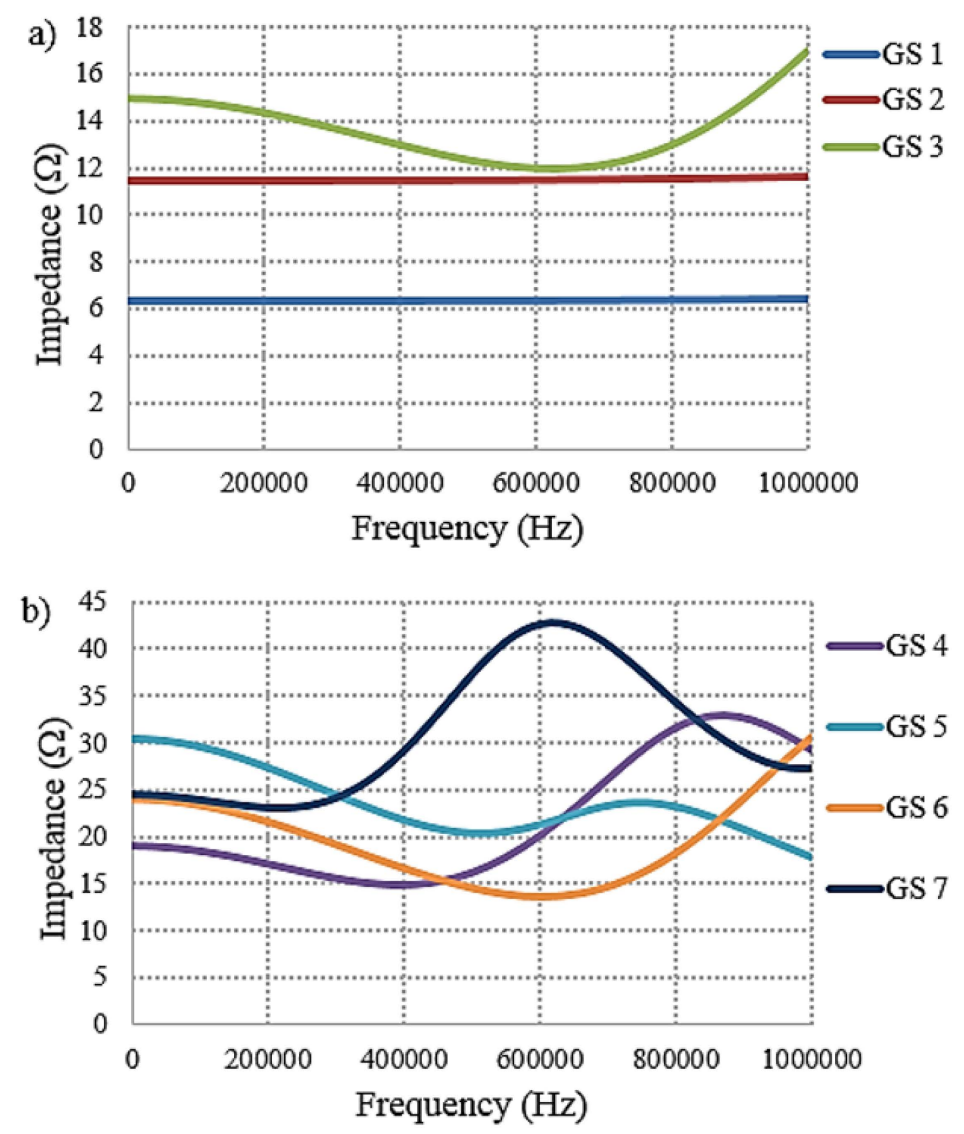

Figure 6. Grounding system impedance vs. frequency (no soil ionization): (a) Concentrated grounding systems; (b) Spatially extended grounding systems. 


\section{Statistical Inputs of the Procedure}

\subsection{Lightning Polarity}

Since lightning polarity influences the generation of the other statistical inputs, it is sampled first, as a random variable uniformly distributed between 0 and 1, assuming that $10 \%$ of flashes to ground are positive.

\subsection{Lightning Parameters}

Log-normal distributions were assumed for lightning stroke parameters (peak current $I_{P}$, front time $t_{F}$ and time-to-half-value $t_{H}$ ), with the values reported in Table 5 [24] for first strokes. Parameters for subsequent negative return-strokes are summarized in Table 6 [24,31], whereas the statistical distribution of multistroke negative lightning flashes is reported in Table 7 [24,31]. According to [24], no correlation between the first and the subsequent stroke peak amplitudes has been assumed.

Table 5. Statistical parameters of first negative and positive return-strokes current.

\begin{tabular}{ccccc}
\hline \multirow{2}{*}{ Parameter } & \multicolumn{2}{c}{ Median Value } & \multicolumn{2}{c}{ Standard Deviation } \\
\cline { 2 - 5 } & - & + & - & + \\
\hline$I_{P}$ & $31.1 \mathrm{kA}$ & $35 \mathrm{kA}$ & 0.48 & 1.21 \\
$t_{F}$ & $3.83 \mu \mathrm{s}$ & $22 \mu \mathrm{s}$ & 0.55 & 1.23 \\
$t_{H}$ & $77.5 \mu \mathrm{s}$ & $230 \mu \mathrm{s}$ & 0.58 & 1.33 \\
\hline
\end{tabular}

Table 6. Statistical parameters of subsequent negative return-strokes current.

\begin{tabular}{ccc}
\hline Parameter & Median Value & Standard deviation \\
\hline$I_{P}$ & $12.3 \mathrm{kA}$ & 0.5296 \\
$t_{F}$ & $0.67 \mu \mathrm{s}$ & 1.0131 \\
$t_{H}$ & $30.2 \mu \mathrm{s}$ & 0.93 \\
\hline
\end{tabular}

Table 7. Statistical distribution of multistroke negative lightning flashes.

\begin{tabular}{cccc}
\hline $\begin{array}{c}\text { Number of } \\
\text { Strokes per Flash }\end{array}$ & $\begin{array}{c}\text { Frequency of } \\
\text { Occurrence (\%) }\end{array}$ & $\begin{array}{c}\text { Number of } \\
\text { Strokes per Flash }\end{array}$ & $\begin{array}{c}\text { Frequency of } \\
\text { Occurrence (\%) }\end{array}$ \\
\hline 1 & 45 & 6 & 4 \\
2 & 14 & 7 & 3 \\
3 & 9 & 8 & 3 \\
4 & 8 & 9 & 2 \\
5 & 8 & 10 or more & 4 \\
\hline
\end{tabular}

\subsection{Line Insulation Parameters}

Critical field $E_{0}$ in the LPM is also treated as a log-normal distributed variable. Median values $E_{0 m}$ and standard deviations [5] are reported in Table 8.

Table 8. Parameters of line insulation.

\begin{tabular}{ccc}
\hline Polarity & Median Value (kV/m) & Standard Deviation $\mathbf{( k V / m )}$ \\
\hline- & 605 & 18.15 \\
+ & 560 & 16.80 \\
\hline
\end{tabular}




\subsection{Lightning Location and Attachment}

To check the actual occurrence of a lightning stroke to the OHL, the position of the lightning in a $1 \mathrm{~km}$ wide strip, centered on the OHL (i.e., its initial distance from the line, assuming a vertical channel), is generated as a random, uniformly distributed variable in the $-500 \mathrm{~m},+500 \mathrm{~m}$ interval. To check lightning attachment to the line, this distance is compared to the attractive radius $R_{a}$ of the OHL, calculated by using the Eriksson's electrogeometric model [25] as:

$$
R_{a}=0.67 \cdot H^{0.6} \cdot I_{P}^{0.74}
$$

where $H$ is the tower height (m).

\subsection{Phase Angle of the Power Frequency Voltage}

A variable uniformly distributed in the range $0^{\circ}-360^{\circ}$ simulates the phase angle of the impressed power frequency voltages (three-phase positive-sequence system).

\section{Results}

For the case under study, the total number of generated lightnings is $N_{t o t}=720,345$, corresponding to 2,153,833 lightning strokes, of which $N_{L}=200,000$ lightning strokes impinge on the line. Figure 7 plots the peak current distribution of the $N_{L}$ lightning strokes. In order to show the self-consistency of the Monte Carlo procedure, i.e., the actual convergence within the given number $N_{\text {tot }}$ of lightning strokes, Figure 8 shows the $100 \cdot\left(N_{B F O} / N\right)$ ratio $v s$. $N$ yielded by the procedure for GS 6 grounding arrangement, for both cases of subsequent strokes disregarded or accounted for (in [32] 100. $\left(N_{B F O} / N\right)$ ratio vs. $N$ trends for GS 1, GS 2 and GS 3 grounding systems are reported). Table 9 summarizes the smallest lightning currents (also the corresponding front times are indicated) causing BFR, both when single flashes and multiple flashes are simulated. Table 10 reports the calculated $100 \cdot\left(N_{B F O} / N\right)$ ratios obtained for the seven different grounding systems with or without subsequent strokes, as well as the corresponding increase of the outage rate due to subsequent strokes.

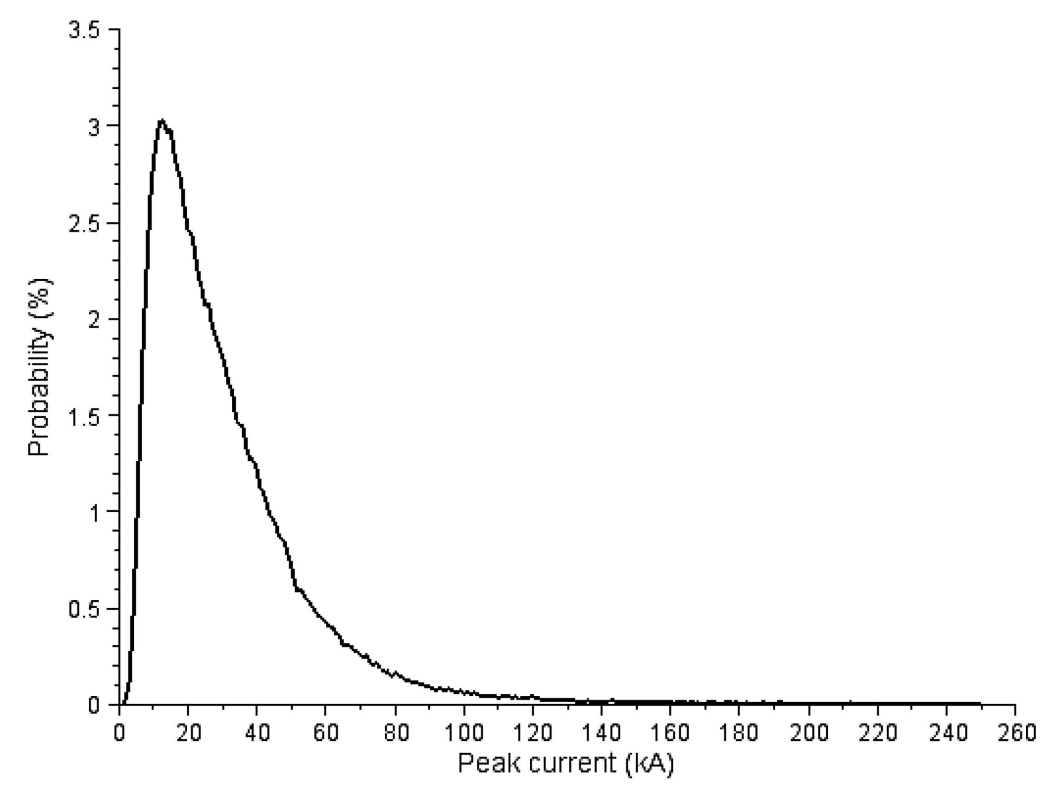

Figure 7. Peak current distribution of lightning strokes impinging on the line. 


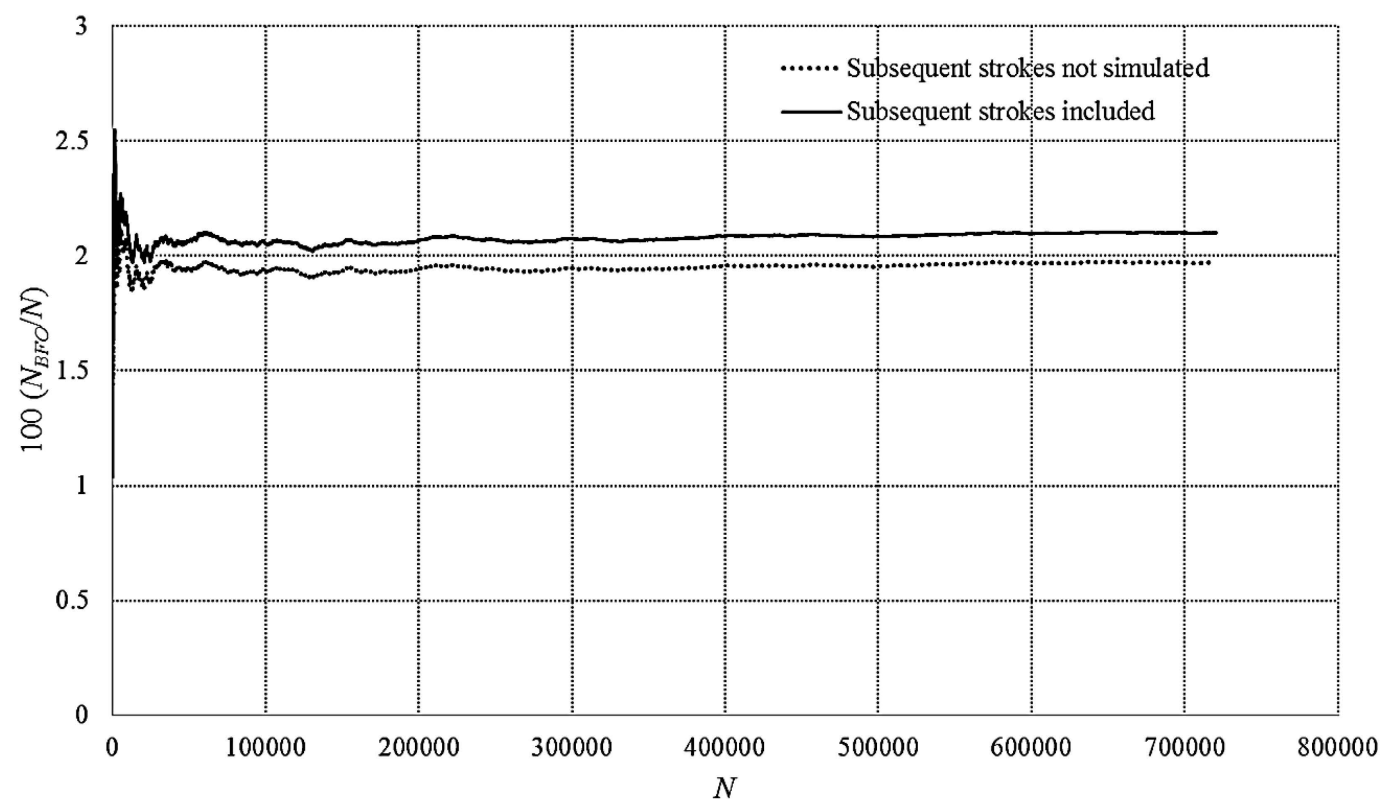

Figure 8. 100 $\left(N_{B F O} / N\right)$ ratio vs. $N$ calculated by the Monte Carlo procedure for GS 6 grounding system.

Table 9. Minimum currents causing backflashover.

\begin{tabular}{cccccc}
\hline \multirow{2}{*}{$\begin{array}{c}\text { Grounding System } \\
\text { Arrangement }\end{array}$} & $\mathbf{R} @ \mathbf{5 0 H z}(\Omega)$ & \multicolumn{2}{c}{$\begin{array}{c}\text { Minimum Current Causing } \\
\text { Backflashover Single Flash }\end{array}$} & \multicolumn{2}{c}{$\begin{array}{c}\text { Minimum Current Causing } \\
\text { Backflashover Multiple Flash }\end{array}$} \\
\cline { 3 - 6 } & & $\mathbf{I}_{P} \mathbf{( k A )}$ & $\boldsymbol{t}_{F}(\boldsymbol{\mu} \mathbf{s})$ & $\boldsymbol{I}_{P}(\mathbf{k A})$ & $\boldsymbol{t}_{F}(\boldsymbol{\mu} \mathbf{s})$ \\
\hline GS 1 & 6.3 & 48.83 & 0.51 & 34.73 & 0.29 \\
GS 2 & 11.42 & 45.11 & 0.59 & 34.73 & 0.29 \\
GS 3 & 14.95 & 43.71 & 0.53 & 34.02 & 0.23 \\
GS 4 & 19.07 & 43.71 & 0.53 & 32.28 & 0.24 \\
GS 6 & 24.05 & 41.91 & 0.61 & 32.11 & 0.23 \\
GS 7 & 24.5 & 35.10 & 0.41 & 29.03 & 0.21 \\
GS 5 & 30.4 & 37.23 & 0.63 & 29.03 & 0.21 \\
\hline
\end{tabular}

Table 10. Calculated $100 \cdot\left(N_{B F O} / N_{t o t}\right)$ ratios and corresponding increases due to the contribution of subsequent strokes.

\begin{tabular}{cccc}
\hline $\begin{array}{c}\text { Grounding System } \\
\text { Arrangement }\end{array}$ & $\begin{array}{c}\mathbf{1 0 0} \cdot\left(\boldsymbol{N}_{B F O} / \boldsymbol{N}_{t o t}\right) \\
\text { Single Flash }\end{array}$ & $\begin{array}{c}\mathbf{1 0 0} \cdot\left(\boldsymbol{N}_{B F O} / \boldsymbol{N}_{\text {tot }}\right) \\
\text { Multiple Flash }\end{array}$ & $\boldsymbol{\Delta} \mathbf{( \% )}$ \\
\hline GS 1 & 0.16 & 0.199 & +24.375 \\
GS 2 & 0.667 & 0.765 & +14.69 \\
GS 3 & 0.781 & 0.844 & +8.06 \\
GS 4 & 1.454 & 1.545 & +6.26 \\
GS 6 & 1.971 & 2.101 & +6.60 \\
GS 7 & 2.678 & 2.913 & +8.78 \\
GS 5 & 3.373 & 3.594 & +6.55 \\
\hline
\end{tabular}

The "overall" peak current distribution for strokes to the OHL in Figure 7 includes both polarities of first strokes, as well as subsequent negative strokes. It still resembles a log-normal probability distribution function, although three different log-normal distributions are superimposed and, moreover, original values are filtered by the electrogeometric model assessment of impingement on the line.

Results in Table 9 show some points: 
- the minimum current causing backflashover strictly depends on R@50Hz for concentrated grounding systems, decreasing as $\mathrm{R} @ 50 \mathrm{~Hz}$ increases;

- for spatially extended grounding systems, the minimum current causing backflashover also depends on the their frequency behavior: for instance, GS 5 has a larger R@50Hz than GS 7, but even a larger minimum current causing backflashover, due to its capacitive behavior at high frequency with respect to the inductive behavior of GS 7 .

BFR results in Table 10 show some important points:

- for concentrated, predominantly resistive, grounding systems GS 1, GS 2 and GS 3, the incorporation of subsequent strokes into the Monte Carlo procedure causes a non-negligible increase of BFR values. A qualitative trend may be evidenced: the impact is noticeably higher (in relative terms) for lower values of low-frequency grounding resistance, as explained in [18];

- for spatially extended grounding systems, the impact of subsequent strokes on BFR depends on the grounding system behavior at high frequencies and is not related to its $\mathrm{R} @ 50 \mathrm{~Hz}$ value. Moreover, the qualitative trend found for concentrated grounding systems does not appear: the impact of subsequent strokes is generally smaller (in relative terms) than for concentrated ones, but not negligible. The largest BFR increase is found in conjunction with the predominantly inductive "counterpoise" grounding system GS 7, caused by the steeper subsequent stroke lightning waves with respect to first strokes, reflecting on a larger $L \frac{d(i)}{d t}$ contribution to the ground potential rise.

Bar charts in Figure 9 and curves in Figure 10 show the distinctive effect of subsequent strokes on BFR for concentrated and spatially extended grounding arrangements, respectively, i.e., the appearance of a narrow but not negligible band of "critical" peak current values to the left of the plot.
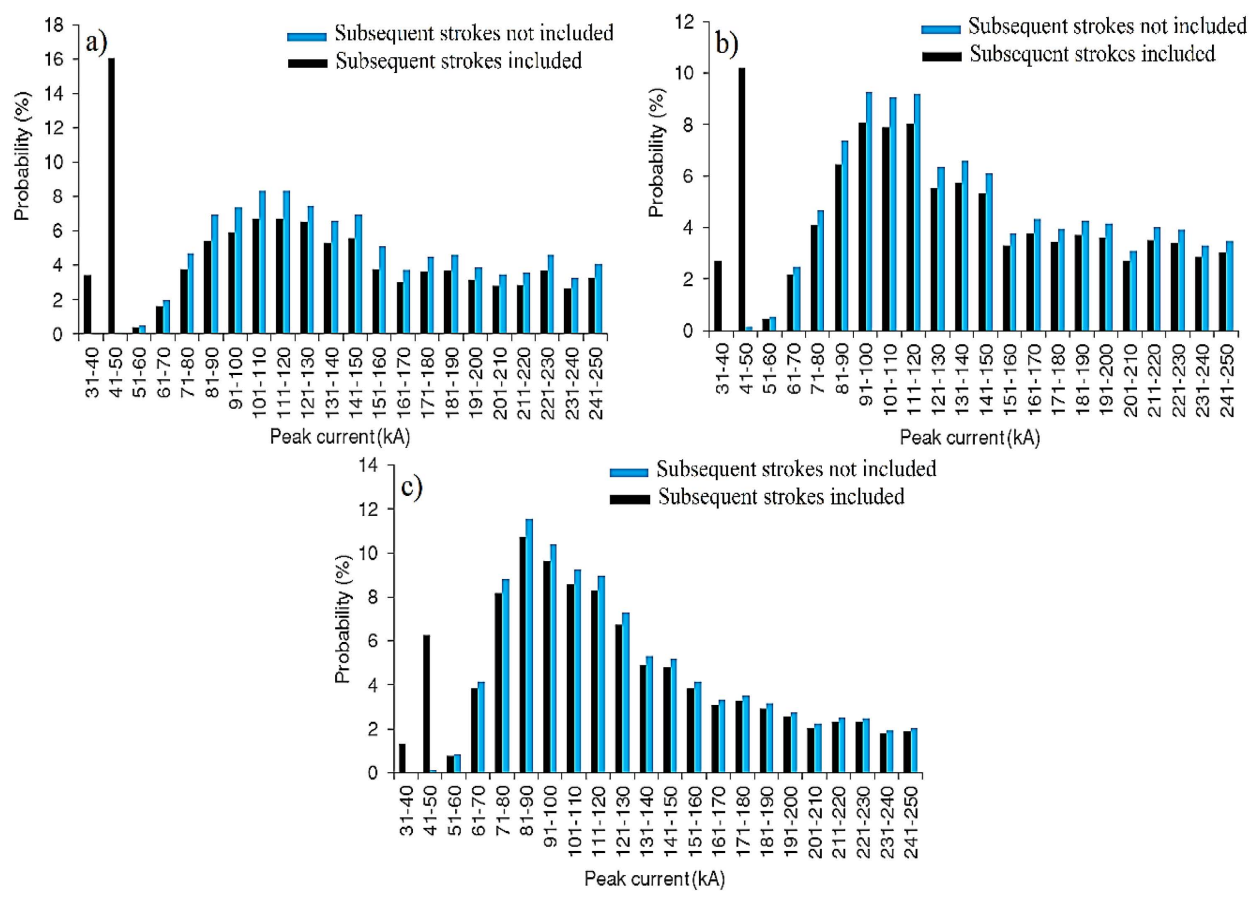

Figure 9. Probability distribution of peak currents resulting in a backflashover. (a) GS 1; (b) GS 2; (c) GS 3 grounding systems. 

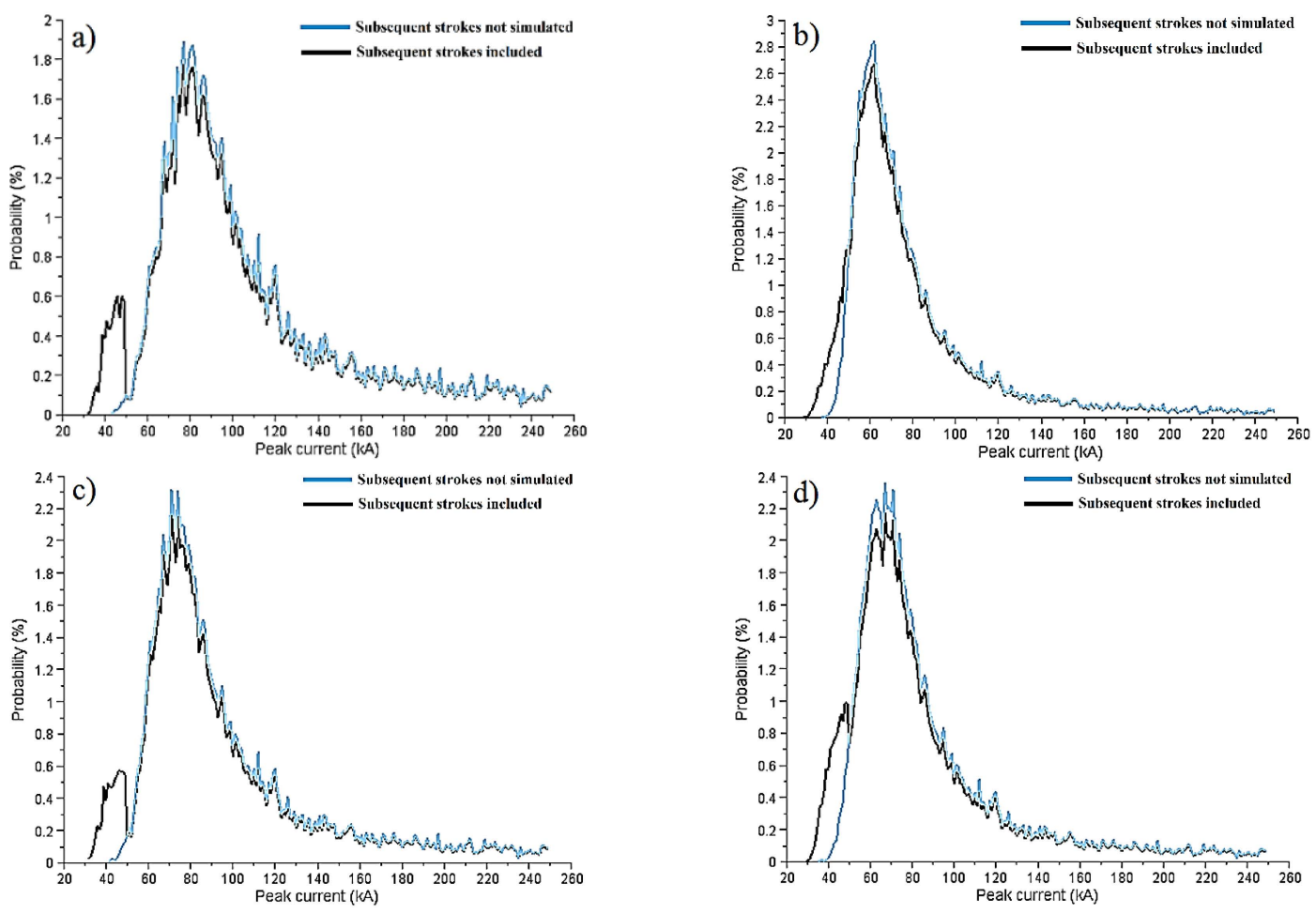

Figure 10. Probability distribution of peak currents resulting in a backflashover. (a) GS 4; (b) GS 5; (c) GS 6; (d) GS 7 grounding systems.

A comparison with prior work, notably the wide-range study in [20], shows that the qualitative trends (BFR vs. low-frequency grounding resistance) are fully consistent, whereas the BFR increases calculated by the authors' procedure are smaller than those in [20]. This quantitative difference is probably due to the different modeling approaches, since [20] simulates grounding systems by a linear lumped resistance, thus disregarding soil ionization, which might be quite significant for spatially concentrated grounding systems in low-resistivity soils, as well as the inductive/capacitive behavior at high frequencies, which is relevant for spatially extended grounding systems.

\section{Conclusions}

The paper presented a comprehensive ATP-EMTP-based Monte Carlo procedure for backflashover assessment, enhancing previous studies with the consideration of the effect of subsequent strokes. Computationally cheap reproduction of the high-frequency behavior of tower grounding systems subjected to the steep lightning current wavefronts of subsequent strokes is allowed by the authors' simple, non-linear, wideband grounding system circuit model. A preliminary study was carried out for a typical Italian $150 \mathrm{kV}$ OHL, considering seven different tower grounding arrangements, three spatially concentrated and four extended. For all cases, a non-negligible impact of subsequent strokes on the BFR estimation was evidenced, with calculated increases ranging between $6 \%$ and $25 \%$. For concentrated, predominantly resistive, grounding systems the incorporation of subsequent strokes into the Monte Carlo procedure causes a non-negligible increase of BFR values. A qualitative trend may be evidenced: the effect of subsequent strokes is noticeably higher (in relative terms) as the "grounding resistance" decreases, as found and explained in previous papers available in literature. From a quantitative point of view, the authors' procedure assesses a smaller increase than those reported in literature, probably due to different modeling approaches: previous papers model grounding systems as linear lumped resistances, thus disregarding soil ionization, which is quite significant for spatially concentrated grounding systems in low-resistivity soils. The response of the different studied spatially extended grounding systems depends on their high frequency behavior, which can be either inductive 
or capacitive. The largest BFR increase is found in conjunction with the predominantly inductive "counterpoise" grounding systems, suggesting that in these cases subsequent strokes should not be neglected. On the other hand, the mainly capacitive "crowfoot" grounding system is less affected, in relative terms, by the inclusion of subsequent strokes: the behavior of such capacitive grounding systems is quite similar to that of resistive grounding systems.

Author Contributions: The authors contributed equally to the work.

Conflicts of Interest: The authors declare no conflict of interest.

\section{References}

1. Geri, A. Behaviour of grounding systems excited by high impulse currents: The model and its validation. IEEE Trans. Power Deliv. 1999, 14, 1008-1017. [CrossRef]

2. Mentre, F.E.; Grcev, L. EMTP-based model for grounding system analysis. IEEE Trans. Power Deliv. 2005, 20, 2200-2210. [CrossRef]

3. Cidras, J.; Otero, A.F.; Garrido, C. Nodal frequency analysis of grounding systems considering the soil ionization effect. IEEE Trans. Power Deliv. 2000, 15, 103-107. [CrossRef]

4. Visacro, S.; Soares, A. HEM: A model for simulation of lightning-related engineering problems. IEEE Trans. Power Deliv. 2005, 20, 1206-1208. [CrossRef]

5. CIGRE Working Group 01 of SC 33. Guide to Procedures for Estimating the Lightning Performance of Transmission Lines; International Council on Large Electric Systems: Paris, France, 1991.

6. IEEE Working Group. A simplified method for estimating lightning performance of transmission lines. IEEE Trans. Power App. Syst. 1985, 104, 919-932.

7. IEEE Working Group. Estimating lightning performance of transmission lines II-Updates to analytical models. IEEE Trans. Power Deliv. 1993, 8, 1254-1267.

8. Anderson, J.G. Monte Carlo computer calculation of transmission line lightning performance. IEEE Trans. Power App. Syst. 1961, 80, 414-419. [CrossRef]

9. Sargent, M.A.; Darveniza, M. The calculation of double circuit outage rate of transmission lines. IEEE Trans. Power App. Syst. 1967, 86, 665-678. [CrossRef]

10. Darveniza, M.; Sargent, M.A.; Limbourn, G.J.; Liew, A.C.; Caldwell, R.O.; Currie, J.R.; Holcombe, B.C.; Stillman, R.H.; Frowd, R. Modeling for lightning performance calculations. IEEE Trans. Power App. Syst. 1979, 98, 1900-1908. [CrossRef]

11. Ekonomou, L.; Gonos, I.F.; Stathopulos, I.A. An improved backflashover model for estimating the lightning performance of transmission lines. In Proceedings of the 38th International Universities Power Engineering Conference (UPEC), Thessaloniki, Greece, 1-3 September 2003; pp. 109-112.

12. Ekonomou, L.; Gonos, I.F.; Stathopulos, I.A.; Dialynas, E.N. A backflashover model for calculating the transmission lines lightning performance. In Proceedings of the 12th International Symposium on High-Voltage Engineering (ISH), Bangalore, India, 20-24 August 2001.

13. Martinez, J.A.; Castro-Aranda, F. Lightning performance analysis of overhead transmission lines using the EMTP. IEEE Trans. Power Deliv. 1994, 9, 1838-1849. [CrossRef]

14. Gatta, F.M.; Geri, A.; Lauria, S.; Maccioni, M. Equivalent Lumped Parameter П-Network of Typical Grounding Systems for Linear and Non-Linear Transient Analysis. In Proceedings of the 2009 IEEE Bucharest Powertech, Bucharest, Romania, 28 June-2 July 2009; pp. 1-6.

15. Gatta, F.M.; Geri, A.; Lauria, S.; Maccioni, M. Simplified HV tower grounding system model for backflashover simulation. In Proceedings of the 30th International Conference on Lightning Protection (ICLP), Cagliari, Italy, 13-17 September 2010; Volume 85, pp. 16-23.

16. Gatta, F.M.; Geri, A.; Lauria, S.; Maccioni, M. Simplified HV tower grounding system model for backflashover simulation. Electr. Power Syst. Res. 2012, 85, 16-23. [CrossRef]

17. Gatta, F.M.; Geri, A.; Lauria, S.; Maccioni, M. Generalized pi-circuit tower grounding model for direct lightning response simulation. Electr. Power Syst. Res. 2014, 116, 330-337. [CrossRef]

18. Silveira, F.H.; Visacro, S.; De Conti, A.; de Mesquita, C.R. Backflashovers of Transmission Lines Due to Subsequent Lightning Strokes. IEEE Trans. Electromagn. Compat. 2012, 54, 316-322. [CrossRef] 
19. Silveira, F.H.; Visacro, S.; de Souza, R.E.; De Conti, A. Assessing the Impact of Subsequent Strokes on the Lightning Performance of Transmission Lines of $138 \mathrm{kV}$. In Proceedings of the 2012 International Conference on Lightning Protection (ICLP), Vienna, Austria, 2-7 September 2012.

20. Silveira, F.H.; Visacro, S.; De Conti, A. Lightning Performance of 138-kV Transmission Lines: The Relevance of Subsequent Strokes. IEEE Trans. Electromagn. Compat. 2013, 55, 1195-1200. [CrossRef]

21. Gatta, F.M.; Geri, A.; Lauria, S.; Maccioni, M.; Santarpia, A. An ATP-EMTP Monte Carlo procedure for backflashover rate evaluation. In Proceedings of the 2012 International Conference on Lightning Protection (ICLP), Vienna, Austria, 2-7 September 2012.

22. Gatta, F.M.; Geri, A.; Lauria, S.; Maccioni, M.; Santarpia, A. An ATP-EMTP Monte Carlo procedure for backflashover rate evaluation: A comparison with the CIGRE method. Electr. Power Syst. Res. 2014, 113, 134-140. [CrossRef]

23. Gatta, F.M.; Geri, A.; Lauria, S.; Maccioni, M.; Palone, F. Tower grounding improvement vs. line surge arresters: comparison of remedial measures for high-BFOR subtransmission lines. IEEE Trans. Ind. Appl. 2015, 51, 4952-4960. [CrossRef]

24. Chowdhuri, P.; Anderson, J.G.; Chisholm, W.A.; Field, T.E.; Ishii, M.; Martinez, J.A.; Marz, M.B.; McDaniel, J.; McDermott, T.R.; Mousa, A.M.; et al. Parameters of lightning strokes: A review. IEEE Trans. Power Deliv. 2005, 20, 346-358.

25. Eriksson, A.J. An Improved Electrogeometric Model for Transmission-Line Shielding Analysis. IEEE Trans. Power Deliv. 1987, 2, 871-886. [CrossRef]

26. Hileman, A.R. Insulation Coordination for Power Systems, 1st ed.; Marcel Dekker, Inc.: New York, NY, USA, 1999.

27. Gatta, F.M.; Geri, A.; Lauria, S.; Maccioni, M. Backflashover simulation of HV transmission lines with enhanced counterpoise groundings. Electr. Power Syst. Res. 2009, 79, 1076-1084.

28. Alternative Transients Program (ATP) Rule Book. Canadian/American EMTP User Group, Oregon, USA, 1995.

29. Heidler, F.; Cvetić, J.M.; Stanić, B.V. Calculation of lightning current parameters. IEEE Trans. Power Deliv. 1999, 14, 399-404.

30. Araneo, R.; Maccioni, M.; Lauria, S.; Geri, A.; Gatta, F.M.; Celozzi, S. Hybrid and Pi-Circuit Approaches for Grounding System Lightning Response. In Proceedings of the 2015 IEEE Eindhoven Powertech, Eindhoven, Netherlands, 29 June-2 July 2015; pp. 1-6.

31. Anderson, R.B.; Eriksson, A.J. A Summary of Lightning Parameters for Engineering Applications. In Proceedings of the International Council on Large Electric Systems, Paris, France, August 1980.

32. Gatta, F.M.; Geri, A.; Lauria, S.; Maccioni, M. Monte Carlo Evaluation of the Impact of Subsequent Strokes on Backflashover Rate. In Proceedings of the 2015 IEEE International Conference on Environment and Electrical Engineering (EEEIC), Rome, Italy, 10-13 June 2015; pp. 1210-1215.

(C) 2016 by the authors; licensee MDPI, Basel, Switzerland. This article is an open access article distributed under the terms and conditions of the Creative Commons by Attribution (CC-BY) license (http://creativecommons.org/licenses/by/4.0/). 